\title{
A global perspective on western Mediterranean precipitation
}

\section{extremes}

\author{
Damián Insua-Costa $\mathbb{D}^{1 凶}$, Martín Senande-Rivera $\mathbb{D i}^{1}$, María Carmen Llasat $\mathbb{D}^{2}$ and Gonzalo Miguez-Macho (D)
}

The Mediterranean region has been declared a climate change hotspot due, among other reasons, to an expected increase in the torrential rains that frequently affect this densely populated area. However, the extent to which these torrential rains are connected to other regions outside the Mediterranean remains uncertain. Here we simulate 160 extreme precipitation events with an atmospheric model enabled for state-of-the-art moisture tracking and demonstrate that large scale moisture transport is a more important factor than evaporation over local sources. We find that the average precipitation fraction with source in the Mediterranean is only $35 \%$, while $10 \%$ is from evapotranspiration over nearby land in continental Europe and $25 \%$ originates in the North Atlantic. The remaining $30 \%$ comes from several more distant source regions, sometimes as remote as the tropical Pacific or the Southern Hemisphere, indicating direct connections with multiple locations on the planet and a global scale energy redistribution. Our results point to the importance of approaching these extreme episodes from a more global rather than purely regional perspective, especially when attempting to attribute them to climate change.

npj Climate and Atmospheric Science (2022)5:9; https://doi.org/10.1038/s41612-022-00234-w

\section{INTRODUCTION}

Determining the origin of the moisture fuelling extreme precipitation events (EPEs) is key to attributing changes in their intensity and frequency to climate change $e^{1,2}$. The Clausius-Clapeyron equation establishes a quasi-exponential increase in humidity with temperature, of about $7 \%$ per degree Celsius, which implies that global warming inevitably leads to more available water vapour in the atmosphere, increasing the odds of heavy rainfall ${ }^{3-5}$. In turn, increased heavy rainfall can enhance flooding and other anthropogenic factors, such as urbanization and deforestation ${ }^{6,7}$, can further intensify this effect. In fact, Europe is currently undergoing an extraordinary flood-rich period, characterized by much higher temperatures than in previous periods of the kind ${ }^{8}$. The search for the moisture sources feeding such flooding events is essential to evaluate whether anomalously high evaporation somewhere, as for example in response to warmer sea surface temperatures, may be enhancing precipitation in them.

Mediterranean countries are particularly affected by these EPEs, which often lead to catastrophic flooding ${ }^{9}$. In some specific cases, up to $800 \mathrm{~mm}$ of rainfall ${ }^{10}$ and up to 1000 deaths $\mathrm{s}^{11,12}$ have been recorded in a single day. Many of these fatal episodes are associated with the development of severe convective systems, whose associated rainfall can be intensified by a temperature rise to a much greater degree than in the case of stratiform precipitation ${ }^{13-15}$. Some studies have already pointed to an increase in the frequency of heavy rainfall in Mediterranean Europe $^{16}$, and climate projections show a strengthening of this trend for the coming years ${ }^{17-23}$.

The formation of these events has traditionally been explained as being a consequence of the potential instability and water vapour content associated with the high heat and evaporation fluxes from the Mediterranean Sea, which in late summer can reach temperatures of $30^{\circ} \mathrm{C}$. However, different studies have suggested that other ocean basins, especially the Atlantic, may contribute significant amounts of moisture to the high precipitation values recorded during these episodes ${ }^{24-32}$. The results provided by these previous studies have therefore opened up an important question: could a very humid flow associated with large-scale circulations outside the Mediterranean be a discriminating factor among many similar local situations in which only one produces an EPE? Or, in other words, are EPEs in the Mediterranean dominated by local-scale mechanisms, or are they more connected to processes in other parts of the planet than previously thought?

The aim of this study is to definitively clarify the origin of the humidity fuelling these catastrophic episodes in southern Europe and, therefore, to identify the regions that should be taken into account when attributing these episodes to global warming. The main novelties of these work are: (1) we use a moisture tagging tool coupled to an atmospheric model ${ }^{33}$, an Eulerian technique that has been considered as representative of "ground truth" due to its high accuracy compared with other moisture tracking methods ${ }^{34,35},(2)$ the domain of study used covers almost the entire Northern Hemisphere in order to assess the influence of possible tropical-extratropical interactions and, in general, potential connections with very distant regions and, finally, (3) we simulate a very large number of EPEs (160). All of which allows us to draw more robust and general conclusions than in previous studies ${ }^{24-32}$, which have generally used qualitative moisture tracking tools and focused on a smaller number of cases and a smaller study region.

\section{RESULTS}

Moisture always comes from multiple sources

The 160 studied EPEs are the strongest registered in the Mediterranean areas of Spain, Andorra, France, and Italy (Fig. 1a) ${ }^{36}$ in the period 1980-2015. Therefore, the results shown below are only valid for the western side of the Mediterranean and

\footnotetext{
${ }^{1}$ CRETUS, Non-linear Physics Group, Universidade de Santiago de Compostela, Galicia, Spain. ${ }^{2}$ Department of Applied Physics, Universitat de Barcelona, Barcelona, Spain.

范mail: damian.insua@usc.es
} 

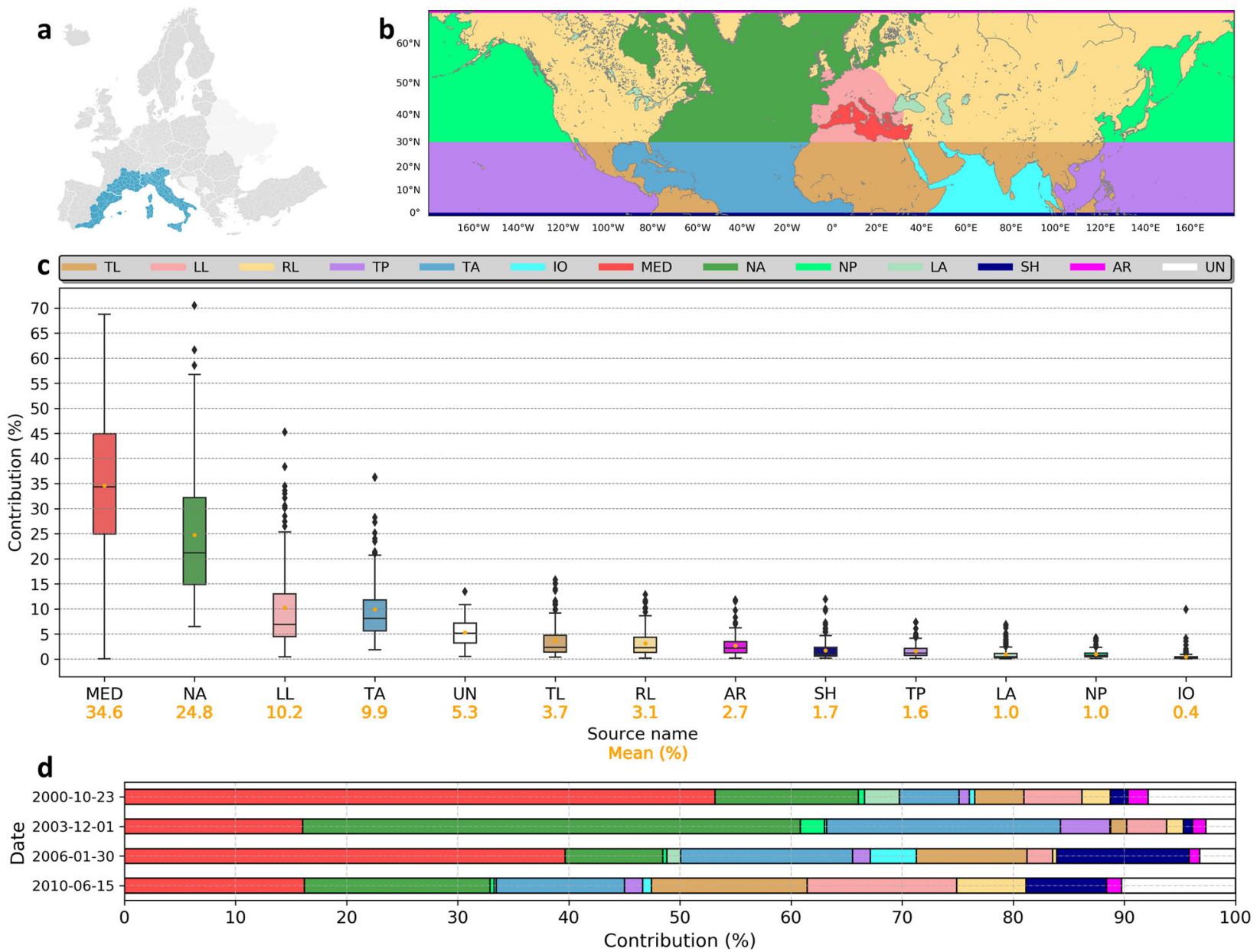

Fig. 1 Precipitation fractions from the different sources. a Region of study in which the extreme precipitation episodes were detected. b Simulation domain and the 12 moisture sources analyzed, which are represented with different colours. All sources are of 2D type, except for those on the northern (magenta) and southern (dark blue) boundaries, which are of 3D type (see Methods section). c Box diagrams for the 160 simulated events according to the moisture source: Tropical Land (TL), Local Land (LL), Remote Land (RL), Tropical Pacific (TP), Tropical Atlantic (TA), Indian Ocean (IO), Mediterranean (MED), North Atlantic (NA), North Pacific (NP), Lakes and Inland Seas (LA), Southern Hemisphere $(\mathrm{SH})$ and Arctic (AR). The abbreviation UN refers to moisture of undefined origin. The orange dot on the diagrams and the orange number on the $x$-axis show the average contribution of each source for the 160 cases. $\mathbf{d}$ Cumulative bar chart with contributions from all sources in four representative cases. The $y$-axis shows the date on which these episodes occurred.

could be substantially different in the eastern part. Figure $1 \mathrm{~b}$ shows the 12 analyzed moisture sources and the semihemispheric domain employed by the atmospheric model enabled for moisture tracking. The simulations are initialized 30 days before the onset of the events to allow sufficient time for moisture to evaporate. Even so, a small fraction of the total rainfall cannot be assigned to any of the 12 sources (white in Fig. 1c, d) because it corresponds to precipitation fed by old moisture, evaporated before the start of the simulations.

The precipitation fractions coming from each source are shown in Fig. 1c, from highest to lowest contribution from left to right. The Mediterranean Sea (red) is the main moisture source with an average input to precipitation of almost $35 \%$. Although variability is high and its maximum contribution is $70 \%$, it is rarely dominant (greater than 50\%). The North Atlantic (dark green) is the second most important source, with an average and maximum percentages of 25 and $70 \%$, respectively. Moisture from local recycling, i.e., moisture evapotranspired over land areas near the study region (light red), has an average contribution of $10.2 \%$ with higher values in warmer months (see Supplementary Fig. 1), occasionally exceeding $40 \%$. The fourth most important contribution is from a very distant source, the tropical Atlantic, with almost $10 \%$ and a maximum above $35 \%$.
Combining the contributions of these four sources, we obtain a precipitation fraction of less than $80 \%$. The remaining $20 \%$ share comes from a string of small contributions from different sources, which together play a fundamental role in intensifying rainfall. In fact, although their average individual contributions are small, variability is high and in some cases, these generally minor sources play a major role. In Fig. 1d we show the precipitation fractions in four relatively recent cases that caused flooding in the Mediterranean region, representing the wide variety and great difference in contributions from one event to another (see Supplementary Fig. 2 for an extended version of this figure). It has been previously pointed out ${ }^{30}$ that a wide variety of sources can contribute to Mediterranean precipitation extremes; however, the precise source contribution numbers have not been quantified until now.

\section{Remote contributions prevail in the most intense cases}

We group all sources into two categories: local, which are those closest to the studied region, i.e., the Mediterranean Sea and surrounding continental lands (red and light red in Fig. 1b) and remote, encompassing the remaining 10 sources, which are farther away. In addition, we have classified the studied events according to their magnitude ${ }^{36}$. The aim is to clarify whether 

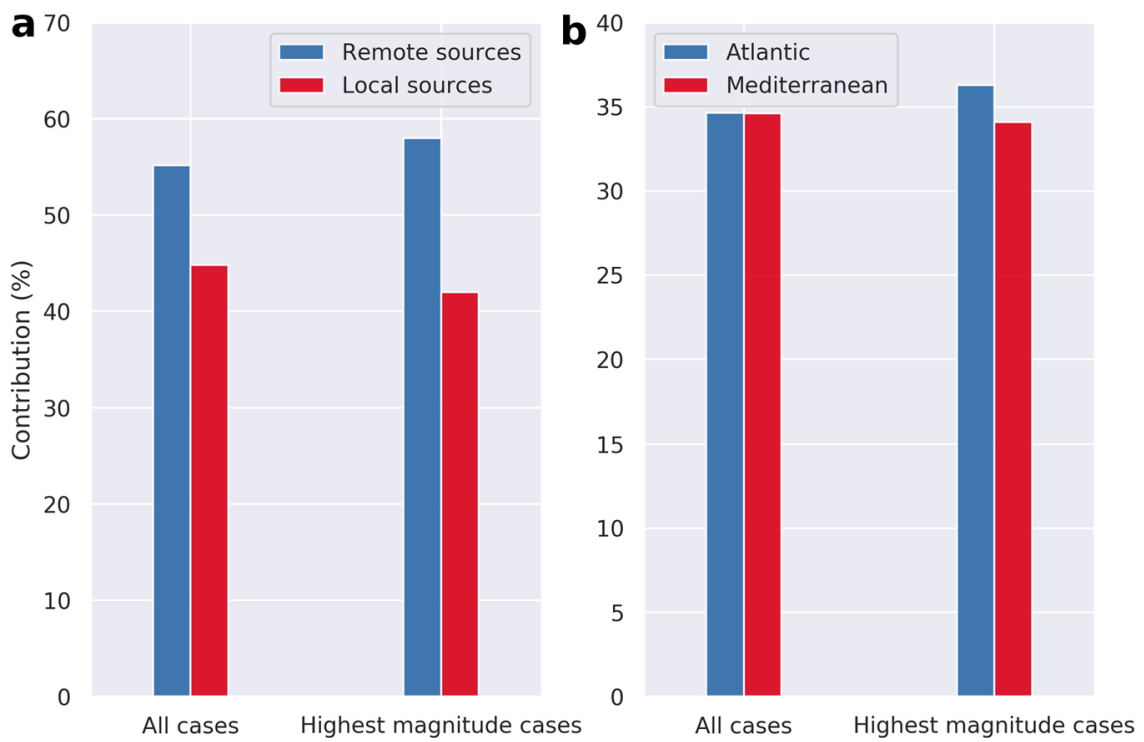

Fig. 2 Comparison between remote and local contributions. a Total contribution from remote sources (blue) versus local sources (red) averaged for all cases studied (left) and for the 25 highest magnitude cases (right). b Same comparison but for the Atlantic Ocean versus the Mediterranean Sea.

moisture from sources outside the Mediterranean is mainly responsible for the precipitation recorded in the most extreme cases.

Figure $2 \mathrm{a}$ shows that for the 160 studied cases, the average contribution of remote sources to precipitation is $10 \%$ higher than that of local sources. This difference is somewhat accentuated if we only consider the 25 most extreme cases, which were associated with major floods ${ }^{36}$. In these catastrophic cases, local sources contributed with slightly more than $40 \%$ and remote sources almost $60 \%$ of the moisture. Considering the main local source and the main remote source (Fig. 2b), i.e., the Mediterranean Sea and the Atlantic Ocean (combining North Atlantic - NA and Tropical Atlantic - TA in Fig. 1), we can see that their average contribution for the total number of cases is practically the same (34.6\% Mediterranean Sea vs. 34.7\% Atlantic). However, in the most extreme cases, the contribution of the Atlantic is marginally higher.

While Atlantic moisture advection maybe especially important for the most extraordinary EPEs in particular areas ${ }^{29}$, we would like to emphasize that, commonly, the difference between the most extreme cases and the rest is small. Therefore, it would not be correct to interpret that in general, extraordinary cases are always dominated by remote sources and that weaker events are always dominated by local ones.

With regard to variations related to atmospheric pattern, we find that the cases associated with the arrival of Atlantic cyclones from the west, both at low and high levels of the atmosphere, have a greater contribution from this oceanic basin, whereas Mediterranean lows, which usually favour south-easterly winds, have a greater Mediterranean contribution (see Supplementary Fig. 3). However, although moisture contributions vary with weather type, neither the Mediterranean nor the Atlantic is predominant (contribution greater than 50\%) on average for any of the atmospheric configurations that usually result in catastrophic precipitation in the western Mediterranean. In particular, our estimates of the contribution of the Mediterranean are lower than in previous studies ${ }^{27,37}$, even for the most favourable synoptic patterns.

\section{High efficiency of Mediterranean water vapour}

In terms of total precipitable water (TPW) contained in the atmospheric column during the events, the contribution of the
Mediterranean Sea is lower than in terms of precipitation. Specifically, the fraction of TPW with Mediterranean origin is $27.4 \%$ on average, about $7 \%$ less than in precipitation (Fig. 3a). For the Atlantic Ocean, the opposite is true, its contribution is higher in terms of TPW (39.4\%) than in terms of precipitation (34.7\%). This shows that Mediterranean water vapour is more efficiently rained than water vapour from remote regions.

The underlying reason lies in the vertical distribution of humidity from the different sources, which violates the wellmixed assumption. This hypothesis, which is implicitly included in many of the numerical models for the study of moisture origin $^{38-42}$, proposes that water vapour is perfectly mixed vertically, so that the fraction of vapour from any moisture source would be independent of height. Our results demonstrate that this assumption does not hold. Figure $3 \mathrm{~b}$ shows that, for the average of the 160 studied cases, the fraction of water vapour from the Mediterranean is much higher at low levels (30-40\%) than at high levels (15-20\%). Since high specific humidity values at low levels are essential to establish a highly potentially unstable environment ${ }^{43}$, we conclude that Mediterranean moisture plays a particularly remarkable role in terms of convective available potential energy. On the contrary, the vapour fraction of Atlantic origin is more important aloft, especially for water vapour coming from the more distant tropical Atlantic. Thus, in the strong convection occurring in these episodes, the total condensate has a higher contribution of low level converging moisture than of entraining water vapour in the updraft at mid and upper levels.

\section{Tropical-extratropical interactions}

Some authors have proposed that tropical moisture exports ${ }^{44}$ could be a precursor of flooding in the Mediterranean region $30,31,45$. The argument is that some extratropical lowpressure systems can descend sufficiently in latitude so as to capture fairly moist air masses from the intertropical convergence zone and advect them into the mid-latitudes via tropical plumes or atmospheric rivers ${ }^{46-48}$, increasing the water vapour content in the atmospheric column in those locations and thus the probability of excessive rainfall. Eastward moving tropical cyclones or their extratropical remnants may also play a key role in some cases, by injecting large amounts of tropical moisture into the Mediterranean basin ${ }^{24,49}$. However, the extent of the influence of 

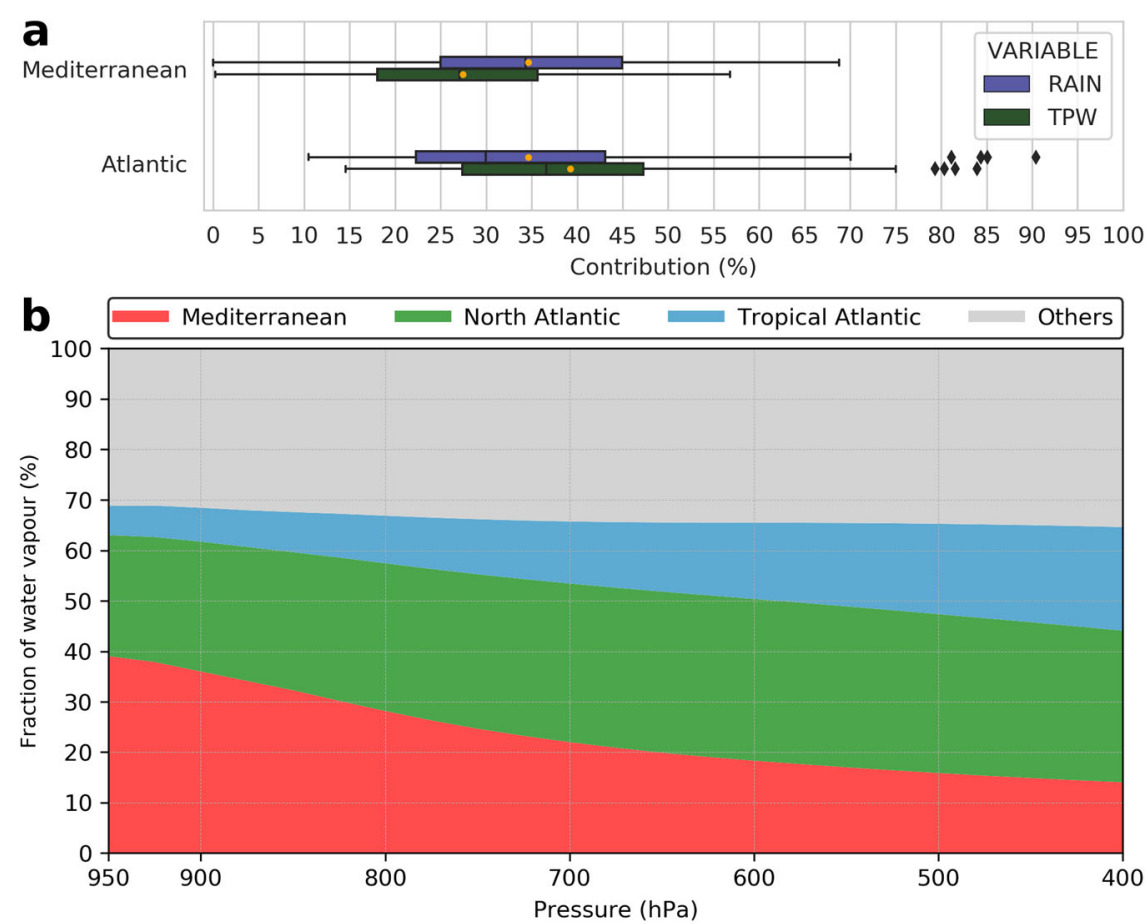

Fig. 3 Vertical distribution of the moisture from the different sources. a Comparison between the Mediterranean and Atlantic contributions to the 160 studied events in terms of rainfall (blue) and total precipitable water (TPW, green). Note that the dots in the lower right corner show the outliers of the Atlantic contributions and that the Mediterranean boxplot has no outliers. b Cumulative plot showing the vertical distribution (in pressure levels) of water vapour fractions from the different sources.

these tropical-extratropical interactions on Mediterranean precipitation extremes remains unclear.

We show that the average percentage of precipitation fed by tropical moisture is $17.3 \%$ (summing TA, Tropical Pacific - TP, Tropical Land - TL, Indian Ocean - IO, and Southern Hemisphere $\mathrm{SH}$ in Fig. 1), with maximum values above $40 \%$. Although most of it (9.9\%) corresponds to tropical Atlantic moisture, in some cases this input can come from much more distant regions. As an example, Fig. 4a shows the precipitable water amount originating in the tropical Pacific region for an extraordinary EPE that affected Catalonia (Spain) in February 1982. More than 5\% (see Supplementary Fig. 2) of the total precipitation can be traced to a moisture plume from that remote tropical Pacific provenance that managed to cross the entire Atlantic. In total, the tropical contribution, in this case, amounted to $34.7 \%$.

Previous studies emphasize the importance of African tropical moisture in some EPEs ${ }^{25,27,31,37,45-48}$. We find that, although its contribution can indeed reach significant values in some cases (up to $15 \%$, Fig. 1c), there could be a misunderstanding in this respect. This is because much of the moisture advected from the interior of the African continent does not actually originate in that area. Figure $4 b-d$, which corresponds to the catastrophic flooding episode of Var (France) in 2010, illustrates this fact adequately. More than $30 \%$ of the rainfall was fed by an African tropical plume (see bottom bar in Fig. 1d). However, the moisture evapotranspirated over tropical land (Fig. $4 \mathrm{~b}$ ) explains only $14 \%$ of the total rainfall. This means that African tropical plumes also transport moisture from other sources, such as are in this Var case, moisture originating in the Southern Hemisphere (7.23\%, Fig. 4c) or in the tropical Atlantic (11.54\%, Fig. 4d). Southern Hemisphere moisture would come mostly from the tropical South Atlantic, with minor contributions from South America and Southern Africa. The comparison between this case (Fig. 4b-d) and that of 1982 (Fig. 4a) also reflects that, although remote moisture inputs in the Mediterranean basin tend to occur via North Africa following the cyclonic circulation typically associated with Mediterranean EPEs (as shown in Supplementary Fig. 3), moisture trajectories further back in time can be very varied.

If we add moisture coming from other extremely distant sources (Remote Land - RL, Arctic - AR, and North Pacific - NP in Fig. 1) to the tropical moisture, we find that on average $24.1 \%$ of the total extreme precipitation in the Mediterranean region is due to moisture transport on scales of several thousand kilometres. This percentage could potentially reach $30 \%$ if we consider that the moisture of undefined origin (5.3\%, Fig. 1c) has a residence time of more than 30 days and, therefore, had probably travelled long distances.

Some authors propose indirect connections between Mediterranean rainfall and climatic anomalies in remote regions, i.e., teleconnections. For example, a positive correlation with El NiñoSouthern Oscillation (ENSO) has been claimed ${ }^{50-52}$. The process that would link both events would be an anomalous atmospheric circulation pattern in the Atlantic Ocean that would appear during El Niño years favouring moisture transport from this basin into the Mediterranean ${ }^{50,51}$. Based on these results, one would expect that Atlantic contributions to Mediterranean EPEs occurred during El Niño years would be higher. However, we do not find a significant correlation between ENSO and the moisture contribution share from the Atlantic, or even from the Pacific to these events (see Supplementary Fig. 4). Therefore, although we do not doubt of the existence of the correlation found between Mediterranean rainfall and ENSO, we question the mechanism put forward to explain such correlation. Rather, our results suggest a more direct connection between the Mediterranean and different parts of the planet. A connection that is direct in the sense that it simply reflects the extensive interrelations within Earth's general atmospheric circulation, whereby evaporation thousands of kilometres away ends up intensifying an EPE in the Mediterranean without the need for any organized anomalous dynamic pattern linking the two processes. This long-distance moisture supply implies energy redistributions of the same scale, which are very relevant for Earth's climate balance. 

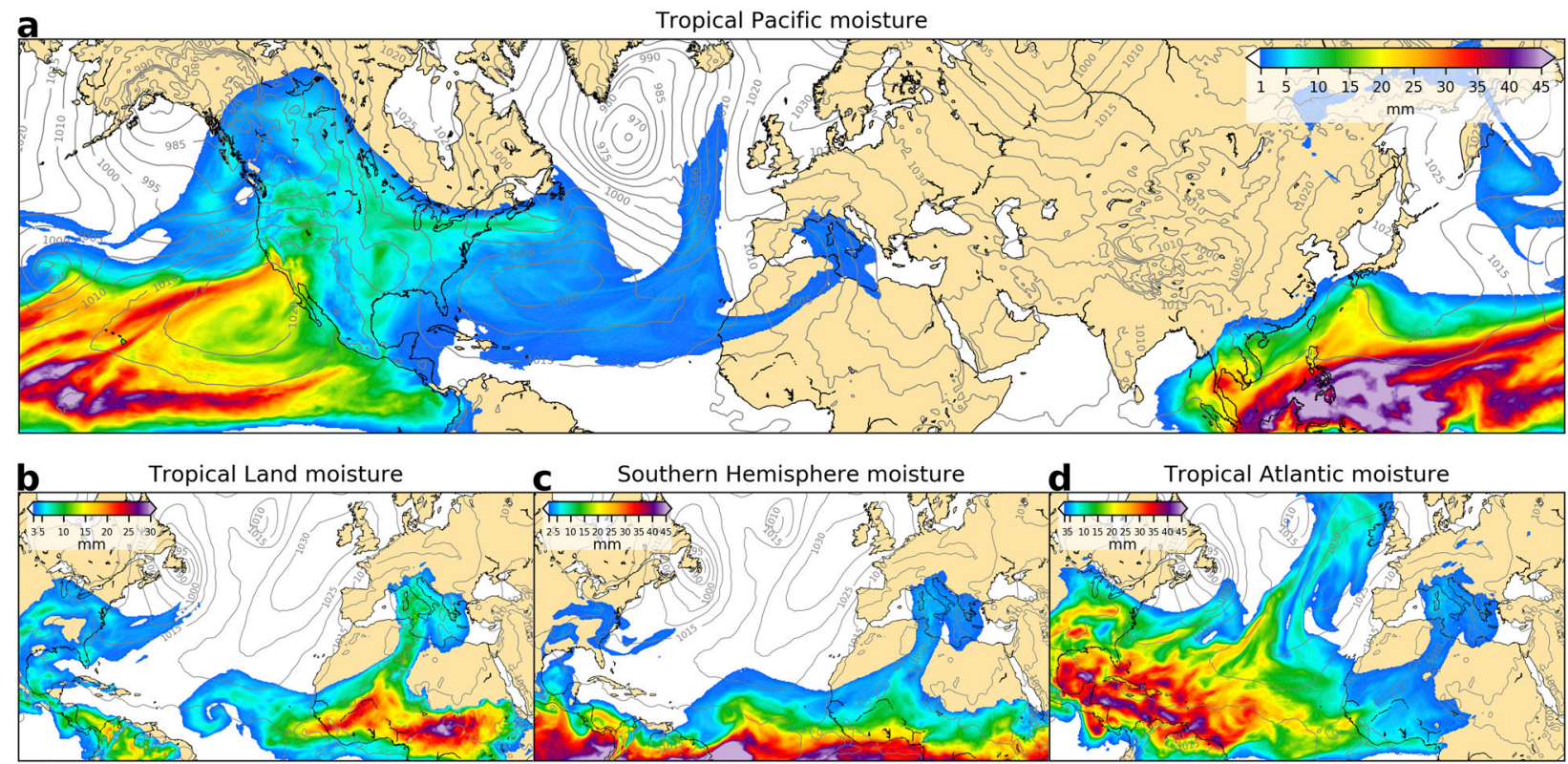

Fig. 4 Tropical moisture exports. Sea level pressure and total precipitable water from evaporation over the tropical Pacific during the February 1982 Catalonia (Spain) extreme precipitation event (a). The same fields but referring to moisture from the tropical land (b), the Southern Hemisphere (c), and the tropical Atlantic (d) during the catastrophic Var (France) flood event in June 2010. Fields are shown at 12 UTC on February 16, 1982 (a) and June 15, 2010 (b-d).

\section{DISCUSSION}

The large precipitation amounts that are usually registered during individual events in the Mediterranean region require high values of water vapour in the atmospheric column to occur. However, with only the moisture provided by the Mediterranean Sea, such high values would hardly be reached. Even adding local recycling and despite the high precipitation efficiency of the low-level Mediterranean humidity, it would generally not be sufficient to produce catastrophic rainfall amounts; thus, a contribution from remote sources is necessary. This contribution from afar is often, but not always, the main input for these events. Moisture transport from the tropics and, in general, from extremely distant sources, plays in many cases an essential role as a precipitation enhancer. Our simulation results suggest that the key contribution of this long distant moisture transport may actually be the norm, not just for the Mediterranean, but elsewhere across the hemisphere as well. Therefore, when studying Mediterranean precipitation extremes, and perhaps extremes in general, in the context of climate change, a global perspective must be taken, considering that alterations in remote regions, for example, of sea surface temperature, can have a direct influence on these potentially catastrophic events.

\section{METHODS}

Daily extreme precipitation event detection and ranking

The 160 analyzed events were extracted from a database of daily hazardous precipitation events covering the period from 1980 to 2015 , which was presented in a previous article ${ }^{36}$. The precipitation data used came from the high-resolution MESCAN gridded precipitation dataset ${ }^{53}$. Events were detected by combining a statistical threshold, based on normalized daily precipitation anomalies, with a constant threshold, set at $60 \mathrm{~mm}$. An event was detected when the daily precipitation in at least one MESCAN grid cell exceeded the combined threshold. Once events were detected, they were ranked according to their magnitude, which was defined based on the recommendations established by the World Meteorological Organization. Specifically, the magnitude of an event was defined using precipitation excess above the threshold and the area affected by it. In the present study, only the 160 events with the highest magnitude were analyzed. To construct Fig. 2 , the top 25 events in the ranking were considered. Supplementary Fig. 5 shows the location and amount of maximum precipitation for each of the 160 studied cases.

\section{Simulation set-up}

For each of the 160 analyzed events, a total of 12 simulations of 31 day duration were performed, one for each studied moisture source. Therefore, the total number of simulations was 1920 , approximately equivalent to a period of 160 years, which involved a high computational cost (about 2 million core-hours). The atmospheric model used was the Weather Research and Forecasting (WRF) version 3.8.1 ${ }^{54}$. This model was configured with a horizontal resolution of $20 \mathrm{~km}$ and a total of 39 vertical levels. The simulation domain (Fig. 1b) had 1416 by 362 grid points, in the east-west and north-south directions, respectively. Since the simulation domain forms a longitudinal belt, periodic boundary conditions were used at the east and west boundaries. Initial and boundary conditions for the northern and southern boundaries were taken from 5th generation of ECMWF (The European Centre for Medium Range Weather Forecasts) global reanalysis $\left(E R A 5^{55}\right)$ and updated every $6 \mathrm{~h}$. As detailed in the main text, the simulations were initialized 30 days prior to the extreme precipitation day under consideration in order to allow sufficient time for moisture to evaporate. If the simulations had been started at a time closer to the event, much of the involved moisture would have already been present at initial time and would not have been tagged by the moisture tracking tool. Importantly, a spectral nudging technique ${ }^{56}$ was employed to prevent the simulation from deviating substantially from the large-scale reanalysis fields, which allowed the model to provide realistic results even 30 days after the start of the simulation. Spectral nudging was applied to geopotential height, horizontal wind, and temperature at all model levels using a nudging coefficient of $0.0008 \mathrm{~s}^{-1}$ and wavenumbers of 58 and 15 in the $x$ and $y$ directions, respectively. Finally, the main parameterizations used were: Yonsei University (YSU) for the boundary layer ${ }^{57}$, WRF singlemoment 6-class (WSM6) for microphysics ${ }^{58}$, and Kain-Fritsch for convec$\operatorname{tion}^{59}$. These parameterizations were selected since they are currently the only ones compatible with the moisture tracking tool ${ }^{33}$. For a validation of the model results, please see Supplementary Fig. 6.

\section{Eulerian-online moisture tracking technique}

The modified WRF model for moisture tracking is named WRF-WVTs and has been validated in depth ${ }^{33}$. Since the moisture tagging tool is coupled to a continuously updated mesoscale atmospheric model, this method incorporates the most advanced knowledge of the physical processes to which atmospheric humidity is subject ${ }^{42}$. 
The technique is similar to the release of a dye into a liquid, which allows the movement of a portion of it to be traced. Continuing with this analogy, in our case, the dye would be applied to each water vapour molecule departing from a certain region of interest, so that they can be distinguished from molecules coming from other sources. Finally, when water vapour condenses and precipitates, one can know the precipitation fraction associated with the dyed molecules, i.e., the fraction coming from the region of interest.

Mathematically, the technique is based on the prognostic equation for moisture:

$$
\frac{\partial q_{\mathrm{n}}}{\partial t}=-\mathbf{v} \cdot \nabla q_{\mathrm{n}}+v_{\mathrm{q}} \cdot \nabla^{2} q_{\mathrm{n}}+\left(\frac{\partial q_{\mathrm{n}}}{\partial t}\right)_{\text {BL }}+\left(\frac{\partial q_{\mathrm{n}}}{\partial t}\right)_{\text {Microphysics }}+\left(\frac{\partial q_{\mathrm{n}}}{\partial t}\right)_{\text {Convection }},
$$

Where $q_{\mathrm{n}}$ refers to the different moisture species considered (water vapour, cloud water, rain water, snow, ice, and graupel). The WRF atmospheric model is modified so that Eq. (1) is replicated, but in this case, the source term due to evaporation (which is considered in the third term on the right-hand side, i.e., in the boundary layer parameterization) is nullified outside of the moisture source region of interest. Therefore, the new equations will prognose tracer moisture, coming from the source of interest. The fields in Fig. 4 are thus obtained by vertically integrating the tracer moisture as follows:

$\mathrm{TPW}=\frac{1}{\rho g} \int_{p_{\mathrm{s}}}^{0} t q(p) \cdot \mathrm{d} p$,

Where TPW is the tracer precipitable water, $t q$ is the tracer moisture (sum of the six species), $p$ is the atmospheric pressure and $\rho$ and $g$ are the water density and gravitational acceleration, respectively.

The equations for total moisture and tracer moisture, which are in Eulerian form, must be solved simultaneously, i.e., online, the reason being that the tracer moisture evolution is subject to the total amount of moisture. For example, the phase changes for tracer moisture must be calculated as a function (proportionally) of the phase changes of the total moisture, and never separately. Finally, the moisture deposition schemes are also replicated to determine the amount of rainfall associated with the tracer moisture, namely the tracer precipitation (TP).

To calculate the precipitation fractions from each analyzed source (Figs. $1 c, d$ and 2), the Mediterranean study region was divided into 7 subregions (see Supplementary Fig. 5). For the calculation of the fractions in a given $E P E$, only those subregions affected by the event were considered, i.e., those where the established precipitation threshold was exceeded. For example, if an event affects regions 1 and 3 , the precipitation fractions (PF) would be calculated as:

$\mathrm{PF}^{k}=\frac{\sum_{i, j \in \mathrm{R} 1} \mathrm{TP}_{i, j}^{k}+\sum_{i, j \in \mathrm{R} 3} \mathrm{TP}_{i, j}^{k}}{\sum_{i, j \in \mathrm{R} 1} P_{i, j}+\sum_{i, j \in \mathrm{R} 3} P_{i, j}}$,

Where $P_{i, j}$ is the total amount of precipitation accumulated at a given grid point $(i, j), \mathrm{TP}_{i, j}^{k}$ is precipitation coming from the " $k$ " moisture source, and $i, j \in \mathrm{R} 1$ refers to the model grid points in region 1 and $i, j \in \mathrm{R} 3$ the model grid points in region 3 . The precipitable water and water vapour fractions in Fig. 3 would be calculated in the same way as the precipitation fractions.

In Eq. (2) " $k$ " ranges from 1 to 12 , since 12 different sources were analyzed. The choice of sources was based primarily on the fact that we were interested in distinguishing between: (1) local and remote, (2) tropical and non-tropical, (3) marine and continental. The sources in the interior of the domain (Fig. 1b) are all of type 2D, i.e., they are used to track the evaporated moisture on them. However, the two sources at the northern and southern end of the domain (AR and SH in Fig. 1b) are of type 3D. This type of source is used to track all the moisture contained in them at any vertical level. In our case, these two 3D sources were selected to track all moisture entering from the northern and southern edge of the domain, i.e., that coming from the Arctic region or the Southern Hemisphere. Thus, this source configuration takes into account all possible moisture sources.

\section{ENSO correlations}

We performed a correlation analysis between precipitation fractions from the Atlantic Ocean and Pacific Ocean and the El Niño 3.4 index $^{60}$. The objective was to check whether in EPEs occurred during the positive ENSO phase, moisture contributions from the Atlantic or the Pacific are higher. For this purpose, Pearson correlation coefficients, which measure the linear relationship between precipitation fractions and the El Niño 3.4 index, were calculated. The statistical significance of this linear relationship is computed from a two-tailed t-test.

\section{DATA AVAILABILITY}

The precipitation fractions from each of the sources for the 160 simulated events can be found in the attached CSV file as supplementary material. All other data generated during the current study are available on request from D.I.C.

\section{CODE AVAILABILITY}

The WRF-WVTs model code is freely available for download at https://github.com/ damianinsua/WRF-WVTs.

Received: 14 September 2021; Accepted: 18 January 2022; Published online: 08 February 2022

\section{REFERENCES}

1. Trenberth, K. E. \& Fasullo, J. T. Climate extremes and climate change: The Russian heat wave and other climate extremes of 2010. J. Geophys. Res. 117, D17103 (2012).

2. Trenberth, K. E., Fasullo, J. T. \& Shepherd, T. G. Attribution of climate extremes. Nat. Clim. Change 5, 725-730 (2015).

3. Allan, R. P. \& Soden, B. J. Atmospheric warming and the amplification of precipitation extremes. Science 321, 1481-1484 (2008).

4. Min, S. K., Zhang, X., Zwiers, F. W. \& Hegerl, G. C. Human contribution to moreintense precipitation extremes. Nature 470, 378-381 (2011)

5. Donat, M. G., Lowry, A. L., Alexander, L. V., O'Gorman, P. A. \& Maher, N. More extreme precipitation in the world's dry and wet regions. Nat. Clim. Change 6, 508-513 (2016).

6. Zhang, W., Villarini, G., Vecchi, G. A. \& Smith, J. A. Urbanization exacerbated the rainfall and flooding caused by hurricane Harvey in Houston. Nature 563, 384-388 (2018).

7. Bradshaw, C. J. A., Sodhi, N. S., Peh, K. S. H. \& Brook, B. W. Global evidence that deforestation amplifies flood risk and severity in the developing world. Glob. Change Biol. 13, 2379-2395 (2007).

8. Blöschl, G. et al. Current European flood-rich period exceptional compared with past 500 years. Nature 583, 560-566 (2020).

9. Llasat, M. C. et al. Towards a database on societal impact of Mediterranean floods in the framework of the HYMEX project. Nat. Hazards Earth Syst. Sci. 13, 1-14 (2013).

10. Ramis, C., Homar, V., Amengual, A., Romero, R. \& Alonso, S. Daily precipitation records over mainland Spain and the Balearic Islands. Nat. Hazards Earth Syst. Sci. 13, 2483-2491 (2013).

11. Barredo, José I. Major flood disasters in Europe: 1950-2005. Nat. Hazards 42, 125-148 (2007).

12. Llasat, M. C., Barriendos, M., Barrera, A. \& Rigo, T. Floods in Catalonia (NE Spain) since the 14th century. Climatological and meteorological aspects from historical documentary sources and old instrumental records. J. Hydrol. 313, 32-47 (2005).

13. Lenderink, G. \& Van Meijgaard, E. Increase in hourly precipitation extremes beyond expectations from temperature changes. Nat. Geosci. 1, 511-514 (2008).

14. Berg, P., Moseley, C. \& Haerter, J. O. Strong increase in convective precipitation in response to higher temperatures. Nat. Geosci. 6, 181-185 (2013).

15. Llasat, M. C., del Moral, A., Cortès, M. \& Rigo, T. Convective precipitation trends in the Spanish Mediterranean region. Atmos. Res. 257, 105581 (2021).

16. Alpert, $P$. et al. The paradoxical increase of Mediterranean extreme daily rainfall in spite of decrease in total values. Geophys. Res. Lett. 29, 31-31 (2002).

17. Sánchez, E., Gallardo, C., Gaertner, M. A., Arribas, A. \& Castro, M. Future climate extreme events in the Mediterranean simulated by a regional climate model: A first approach. Glob. Planet. Change 44, 163-180 (2004).

18. Gao, X., Pal, J. S. \& Giorgi, F. Projected changes in mean and extreme precipitation over the Mediterranean region from a high resolution double nested RCM simulation. Geophys. Res. Lett. 33, L03706 (2006).

19. Goubanova, K. \& Li, L. Extremes in temperature and precipitation around the Mediterranean basin in an ensemble of future climate scenario simulations. Glob. Planet. Change 57, 27-42 (2007).

20. Tramblay, Y. \& Somot, S. Future evolution of extreme precipitation in the Mediterranean. Clim. Change 151, 289-302 (2018).

21. Cortès, M. et al. Changes in flood damage with global warming on the eastern coast of Spain. Nat. Hazards Earth Syst. Sci. 19, 2855-2877 (2019).

22. Cramer, W., Guiot, J. \& Marini, K. MedECC climate and environmental change in the Mediterranean basin-current situation and risks for the future. First Mediterranean Assessment Report. 633pp https://doi.org/10.5281/zenodo.4768833 (2020). 
23. Zittis, G., Bruggeman, A. \& Lelieveld, J. Revisiting future extreme precipitation trends in the Mediterranean. Weather. Clim. Extremes 34, 100380 (2021).

24. Reale, O., Feudale, L. \& Turato, B. Evaporative moisture sources during a sequence of floods in the Mediterranean region. Geophys. Res. Lett. 28, 2085-2088 (2001).

25. Turato, B., Reale, O. \& Siccardi, F. Water vapor sources of the October 2000 Piedmont flood. J. Hydrometeorol. 5, 693-712 (2004).

26. Nieto, R., Gimeno, L., Drumond, A. \& Hernandez, E. A Lagrangian identification of the main moisture sources and sinks affecting the Mediterranean area. WSEAS Trans. Environ. Dev. 6, 365-374 (2010).

27. Duffourg, F. \& Ducrocq, V. Origin of the moisture feeding the heavy precipitating systems over Southeastern France. Nat. Hazards Earth Syst. Sci. 11, 1163-1178 (2011).

28. Winschall, A., Pfahl, S., Sodemann, H. \& Wernli, H. Impact of North Atlantic evaporation hot spots on southern Alpine heavy precipitation events. Q. J. Roy. Meteorol. Soc. 138, 1245-1258 (2012).

29. Pinto, J. G. et al. Identification and ranking of extraordinary rainfall events over Northwest Italy: The role of Atlantic moisture. J. Geophys. Res.-Atmos. 118, 2085-2097 (2013).

30. Winschall, A., Sodemann, H., Pfahl, S. \& Wernli, H. How important is intensified evaporation for Mediterranean precipitation extremes? J. Geophys. Res.-Atmos. 119, 5240-5256 (2014)

31. Krichak, S. O., Barkan, J., Breitgand, J. S., Gualdi, S. \& Feldstein, S. B. The role of the export of tropical moisture into midlatitudes for extreme precipitation events in the Mediterranean region. Theor. Appl. Climatol. 121, 499-515 (2015).

32. Insua-Costa, D., Miguez-Macho, G. \& Llasat, M. C. Local and remote moisture sources for extreme precipitation: A study of the two catastrophic 1982 western Mediterranean episodes. Hydrol. Earth Syst. Sci. 23, 3885-3900 (2019).

33. Insua-Costa, D. \& Miguez-Macho, G. A new moisture tagging capability in the Weather Research and Forecasting model: Formulation, validation, and application to the 2014 Great Lake-effect snowstorm. Earth Syst. Dyn. 9, 167-185 (2018).

34. Van der Ent, R. J., Tuinenburg, O. A., Knoche, H. R., Kunstmann, H. \& Savenije, H. H. $\mathrm{G}$. Should we use a simple or complex model for moisture recycling and atmospheric moisture tracking? Hydrol. Earth Syst. Sci. 17, 4869-4884 (2013).

35. Goessling, H. F. \& Reick, C. H. On the "well-mixed" assumption and numerical 2-D tracing of atmospheric moisture. Atmos. Chem. Phys. 13, 5567-5585 (2013).

36. Insua-Costa, D., Lemus-Cánovas, M., Miguez-Macho, G. \& Llasat, M. C. Climatology and ranking of hazardous precipitation events in the western Mediterranean area. Atmos. Res. 255, 105521 (2021).

37. Duffourg, F. \& Ducrocq, V. Assessment of the water supply to Mediterranean heavy precipitation: A method based on finely designed water budgets. Atmos. Sci. Lett. 14, 133-138 (2013).

38. Brubaker, K. L., Entekhabi, D. \& Eagleson, P. S. Estimation of continental precipitation recycling. J. Clim. 6, 1077-1089 (1993).

39. Eltahir, E. A. B. \& Bras, R. L. Precipitation recycling. Rev. Geophys. 34, 367-378 (1996)

40. Dirmeyer, P. A. \& Brubaker, K. L. Contrasting evaporative moisture sources during the drought of 1988 and the flood of 1993. J. Geophys. Res.-Atmos. 104, 19383-19397 (1999).

41. Van der Ent, R. J., Savenije, H. H., Schaefli, B. \& Steele-Dunne, S. C. Origin and fate of atmospheric moisture over continents. Wat. Resour. Res. 46, W09525 (2010).

42. Gimeno, L. et al. Oceanic and terrestrial sources of continental precipitation. Rev. Geophys. 50, RG4003 (2012).

43. Taszarek, M., Allen, J. T., Marchio, M. \& Brooks, H. E. Global climatology and trends in convective environments from ERA5 and rawinsonde data. NPJ Clim. Atmos. Sci. 4, 1-11 (2021).

44. Knippertz, P. \& Wernli, H. A Lagrangian climatology of tropical moisture exports to the Northern Hemispheric extratropics. J. Clim. 23, 987-1003 (2010).

45. Wu, M.-L. C., Reale, O. \& Schubert, S. D. A characterization of African easterly waves on 2.5-6-day and 6-9-day time scales. J. Clim. 26, 6750-6774 (2013).

46. Ziv, B. A subtropical rainstorm associated with a tropical plume over Africa and the Middle-East. Theor. Appl. Climatol. 69, 91-102 (2001).

47. Rubin, S., Ziv, B. \& Paldor, N. Tropical plumes over eastern North Africa as a source of rain in the Middle East. Mon. Weather Rev. 135, 4135-4148 (2007).

48. Lorente-Plazas, R. et al. Unusual atmospheric-river-like structures coming from Africa induce extreme precipitation over the western Mediterranean Sea. J. Geophys. Res. Atmos. 125, e2019JD031280 (2020).

49. Pinto, J. G., Klawa, M., Ulbrich, U., Rudari, R. \& Speth, P. Extreme precipitation events over north-west Italy and their relationship with tropical-extratropical interactions over the Atlantic. In Proc. Third EGS Plinius Conf. on Mediterranean Storms, Baja Sardinia 321-332 (2001).

50. Mariotti, A., Zeng, N. \& Lau, K.-M. Euro-Mediterranean rainfall and ENSO-a seasonally varying relationship. Geophys. Res. Lett. 29, 1621-1625 (2002).

51. Shaman, J. \& Tziperman, E. An atmospheric teleconnection linking ENSO and southwestern European precipitation. J. Clim. 24, 124-139 (2011).

52. Krichak, S. O., Breitgand, J. S., Gualdi, S. \& Feldstein, S. B. Teleconnection-extreme precipitation relationships over the Mediterranean region. Theor. Appl. Climatol. 117, 679-692 (2014).
53. Soci, C., Bazile, E., Besson, F. \& Landelius, T. High-resolution precipitation re-analysis system for climatological purposes. Tellus A 68, 29879 (2016).

54. Skamarock, W. C. et al. A Description of the Advanced Research WRF Version 3 Tech. Note NCAR/TN-475+STR (Mesoscale and Microscale Meteorology Division, National Center for Atmospheric Research, 2008).

55. Hersbach, $\mathrm{H}$. et al. The ERA5 global reanalysis. Q. J. Roy. Meteor. Soc. 146 1999-2049 (2020).

56. Miguez-Macho, G., Stenchikov, G. L. \& Robock, A. Spectral nudging to eliminate the effects of domain position and geometry in regional climate model simulations. J. Geophys. Res. 109, D13104 (2004).

57. Hong, S. Y., Noh, Y. \& Dudhia, J. A new vertical diffusion package with an explicit treatment of entrainment processes. Mon. Weather Rev. 134, 2318-2341 (2006)

58. Hong, S. Y. \& Lim, J. O. J. The WRF single-moment 6-class microphysics scheme (WSM6). J. Korean Meteorol. Soc. 42, 129-151 (2006).

59. Kain, J. S. The Kain-Fritsch convective parameterization: An update. J. Appl. Meteorol. 43, 170-181 (2004).

60. Rayner, N. A. A. et al. Global analyses of sea surface temperature, sea ice, and night marine air temperature since the late nineteenth century. J. Geophys. Res. Atmos. 108, 4407 (2003).

\section{ACKNOWLEDGEMENTS}

Funding comes from the Spanish Ministerio de Economia y Competitividad OPERMO (CGL2017-89859-R to G.M.M., D.I.C., and M.S.R.) and M-CostAdapt (CTM2017-83655 C2-2-R to M.C.LL.) projects, the European Union Interreg V POCTEFA project (EFA210/ 16 PIRAGUA to M.C.LL.) and the CRETUS strategic partnership (AGRUP2015/02 to G.M.M., D.I.C., and M.S.R.). All these programs are co-funded by the European Union ERDF. M.S.R. acknowledges Xunta de Galicia for a predoctoral grant (Programa de axudas á etapa predoutoral 2019, ED481A 2019/112). D.I.C. was awarded a predoctoral FPI (PRE2018-084425) grant from the Spanish Ministry of Science, Innovation and Universities. Computation took place at CESGA (Centro de Supercomputación de Galicia), Santiago de Compostela, Galicia, Spain.

\section{AUTHOR CONTRIBUTIONS}

D.I.C. designed the experiment, performed the simulations, created the figures, and wrote the first manuscript draft. M.S.R. was in charge of part of the data analysis. G.M.M., M.S.R., and M.C.L.L. contributed with ideas, interpretation of the results, and manuscript revisions.

\section{COMPETING INTERESTS}

The authors declare no competing interests.

\section{ADDITIONAL INFORMATION}

Supplementary information The online version contains supplementary material available at https://doi.org/10.1038/s41612-022-00234-w.

Correspondence and requests for materials should be addressed to Damián InsuaCosta.

Reprints and permission information is available at http://www.nature.com/ reprints

Publisher's note Springer Nature remains neutral with regard to jurisdictional claims in published maps and institutional affiliations.

Open Access This article is licensed under a Creative Commons Attribution 4.0 International License, which permits use, sharing, adaptation, distribution and reproduction in any medium or format, as long as you give appropriate credit to the original author(s) and the source, provide a link to the Creative Commons license, and indicate if changes were made. The images or other third party material in this article are included in the article's Creative Commons license, unless indicated otherwise in a credit line to the material. If material is not included in the article's Creative Commons license and your intended use is not permitted by statutory regulation or exceeds the permitted use, you will need to obtain permission directly from the copyright holder. To view a copy of this license, visit http://creativecommons. org/licenses/by/4.0/.

(c) The Author(s) 2022 